\title{
CONTENTS
}

Acknowledgments ix

Introduction

Bruce Horner, Brice Nordquist, and Susan M. Ryan 3

\section{INSTITUTIONAL/DISCIPLINARY ECONOMIES}

1. The Politics of Valuation in Writing Assessment

Tony Scott 13

2. (Re)writing Economies in a Community College: Funding, Labor, and Basic Writing

Katie Malcolm 30

3. Dwelling Work and the Teaching of Writing: Responding to the Pressures of For-Profit Instruction

Steve Lamos 43

4. Occupying Research-Again/Still

Joan Mullin and Jenn Fishman 55

5. The Political Economy of English: The "Capital" of Literature, Creative Writing, and Composition

James T. Zebroski 68

\section{ECONOMIES OF WRITING PEDAGOGY AND CURRICULUM}

6. Economies of Knowledge Transfer and the Use-Value of First-Year Composition

Anis Bawarshi 87

7. Symbolic Capital in the First-Year Composition Classroom

Yuching Jill Yang, Kacie Kiser, and Paul Kei Matsuda 99 
8. A Question of Mimetics: Graduate-Student Writing Courses and the New "Basic"

Kelly Ritter 112

9. Commodifying Writing: Handbook Simplicity versus Scholarly Complexity

Samantha Looker 131

10. Psychoanalysis, Writing Pedagogy, and the Public: Toward a New Economy of Desire in the Classroom and in Composition Studies

T. R. Johnson 145

III ECONOMIES OF LANGUAGE AND MEDIUM

11. Literate Resources and the Contingent Value of Language

Rebecca Lorimer Leonard 161

12. The Rhetoric of Economic Costs and Social Benefits in US Healthcare Language Policy

Scott Wible 172

13. Web 2.0 Writing as Engine of Information Capital

Christian J. Pulver 191

14. www.engl.ish: Internationalized World Wide Web Domains and Translingual Complexities

Jay Jordan 203

IV PUBLIC WRITING ECONOMIES

15. Habermasochism: The Promise of Cyberpublics in an Information Economy

Donna LeCourt 225

16. Tierra Contaminada: Economies of Writing and Contaminated Ground

Jason Peters 238

17. Democratic Rhetoric in the Era of Neoliberalism

Phyllis Mentzell Ryder 252 
Afterword: Lessons Learned

Deborah Brandt 269

References 273

About the Authors 295

Index 299

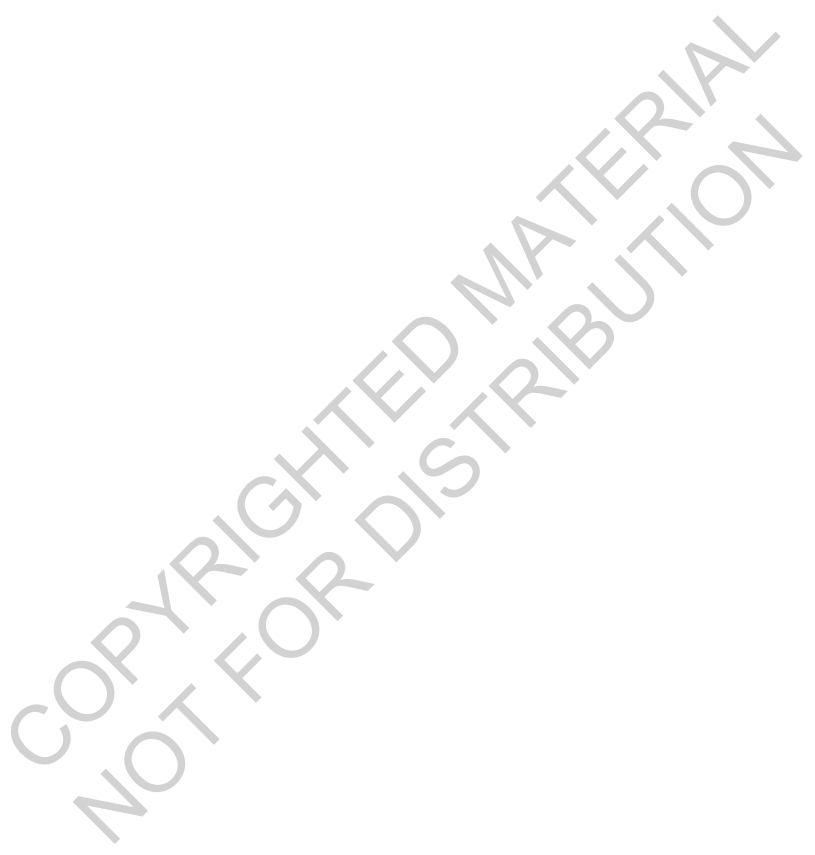




\title{
THE POLITICS OF VALUATION IN WRITING ASSESSMENT
}

\author{
Tony Scott
}

Two contrasting situations have become familiar tropes of writing program administration and writing assessment scholarship in our field. Chris Gallagher (2009, 29-30) opens an article about assessment in Writing Program Administration with the description of one scenario in which university administrators are seeking to impose standardized assessments on a first-year writing program. The administrators are tying assessment to efficiency, centralized quality control, and accountability. Looming ominously within the scene is the Spellings Commission Report, which uses crisis rhetoric to call for an overhaul of higher education that has efficiency and accountability (typically code for mandated large-scale assessment) as central elements; also looming is the testing/textbook/ curriculum industry, which has become an important, politically active driver of state-imposed assessment mandates on higher education across the country. After presenting this daunting scenario, Gallagher offers a contrasting scenario in which the writing program administrator (WPA) is respected and placed in a position of agency. The empowered WPA in the more positive scenario is recognized by interdisciplinary colleagues and higher-level administrators for expertise in writing, and she is initiating informed, democratic assessment practices with teachers that have positive effects in classes across campus (30).

Cindy Moore, Peggy O’Neill, and Brian Huot open an influential article in College Composition and Communication with similarly contrasting situations. In the first, a dean initiates contact with a WPA to seek advice about assessment in a writing-across-the-curriculum initiative. Moore, O'Neill, and Huot (2009) see this as an important development for its "implied message about the potential role of the composition director in the broad-based assessment this dean is beginning to imagine" (108). As with Gallagher's more positive scenario, here the WPA is in a position of power that comes from institutionally recognized expertise in 
both assessment and writing. She is not only able to shape how writing is conceived and assessed in the writing program, she is also able to shape assessment policy across campus. The article then describes contrasting, negative scenarios, which, the authors acknowledge, are common enough to have become established lore in the field. Here, assessments are imposed from outside, and WPAs are forced to work within narrow parameters that offer little autonomy for the writing program and little control over how scores will be used (108-9).

The problem posed in both articles is, How we might do assessment constructively, responsibly, and in a way consistent with current scholarly understandings of writers and writing, under circumstances not yet of our making? The responses to the problem are nearly always individualistic and focus primarily on the actions, rhetorical acumen, and agentive scope of the WPA, who represents the seemingly unified interests of an entire writing program. A minimum requirement is that the WPA learn about assessment. Moore, O'Neill, and Huot (2009) advocate a fairly deep and rigorous knowledge that includes understanding of complex conversations in psychometrics and educational measurement. Gallagher (2009) advocates a perhaps more familiarly compositionsituated expertise that combines a current understanding of writing pedagogy with a general understanding of technical concepts in assessment. Both envision responses to assessment challenges that involve a rhetorically adept WPA who, lacking institutionally conferred agency and expertise in writing education, must create the conditions for it through the power of persuasion.

The trope of the can-do, rhetorically savvy, resourceful WPA holds its own place in the WPA scholarship. In her award-winning monograph, The Activist WPA, Linda Adler-Kassner (2008) offers frameworks WPAs might use to build relationships and coalitions across campuses and beyond to secure resources. While the techniques are drawn from activism, the purposes to which they are put are hardly radical-to create the conditions for a responsible and effective writing program. Kelly Ritter (2006, 61) similarly advocates that WPAs go public, outside of institutional structures, to gain a "hard-fought" authority not conferred institutionally and to secure seemingly basic operational resources. She advocates negotiating and building consensus with a broad swath of people-upper-level university administrators, regional WPAs, trustees on the school board, feeder institutions, high schools, and state boards of higher education. All of this work is to happen, one imagines, in addition to the demanding day-to-day work of actually administering a writing program. 
What are the conditions that have led WPAs to envision this superbly skilled, tireless, and self-sacrificing professional paragon whose primary goal is to overcome considerable institutional friction-only to responsibly do what the institution mandates? How does the function of WPAs as skilled negotiators and assessment experts relate to the agency and conditions of the TAs and contracted part- and full-time non-tenure-track instructors who teach most writing classes? Why, when so many first-year writing programs aren't regularly resourced at minimally responsible levels and in a time of austerity in higher education, is there such a strong push at state and federal levels to mandate writing assessments? In this chapter, drawing on my experiences with designing and implementing program assessments as a WPA, I further examine the political economic implications of large-scale writing assessment and how it relates to management/labor dynamics in composition. Though technical expertise in assessment is certainly important, so too is critical understanding of the persistent political economic ordering functions of assessment. I argue that a vital but largely missing element of the assessment scene in the scholarship involves labor struggle, or how assessment functions as a means of misrepresenting and ordering the labor of teachers and students through controlling the terms of its valuation. The push to make writing labor (teaching and composing) a commodity, an exchangeable unit divorced from material situations and laboring bodies, extends from a neoliberal political economic ideology that seeks economization of all human relations according to a singular model of efficiency, competition, and concentrated accumulation. I argue that large-scale writing assessment mandates function as a means of making the terms of labor invisible through shifting the focus from the qualitative to the quantitative, from multiplicity to singularity, and from the agentive exercise of professional expertise to the ordered achievement of symbolic outcomes.

\section{DIFFERENT REPRESENTATIONS, DIFFERENT ORDERS}

In Testing Testing: Social Consequences of the Examined Life, Allan Hanson (1993) argues that assessment is ubiquitous in contemporary Western life because it serves as a means of imposing order and discipline. Hanson describes practices as varied as medieval witch tests, drug tests, polygraph tests, and standardized achievement tests that help to maintain order through enforcing and clarifying culturally/politically sanctioned categories. Testing therefore serves to create boundaries, hierarchies, and representations according to the dominant assumptions of a time and place. 
I offer another WPA assessment scenario drawn from my past experience, one I will describe with emphasis on how it represents and orders labor. ${ }^{1}$ As an accreditation review approached at a large, public university in the Southeast, a dean was placed in charge of assessment across all colleges and units. The university had an assessment officer who, in coordination with the dean, developed an interpretation of the requirements of the accreditation body. Based on that interpretation, a set of assessment guidelines and a reporting process were developed. As WPA, I was told to design and implement my own assessment of the writing program. However, we were required to use formalized procedures designed to respond to accreditation reporting guidelines, and all assessing units were required to report using the same form.

This requirement was important because the form was not philosophically neutral. It framed assessment in terms of deficit location and diagnosis at the programmatic level and it reflected an objectivist perspective on measurement (a copy of the reporting form is included in Appendix 1.A). The ordering "story" the form is designed to create is that

- We have deficits in teaching in the program occurring across classrooms.

- Those deficits can be identified and quantified through the reliable evaluation of students' texts, where they will manifest in aggregate.

- Those deficits can be remedied programmatically, and the results of the remedy should show in the next round of assessment. The program structure is such that this instrumental action is possible.

- What we value in student writing and how we value it is necessarily constant over time. If we don't maintain the same stated outcomes, and the same means of measuring those outcomes, there is no means of comparison between assessment years, no way of tracking progress or regression. So the assessment mandate also requires stasis. We must close the discussion of what we value and how we assess: in this endless growth model, the premium is on comparison and directed change over years.

- Assessment is positivistic and objective. Through sound measurement and adjustment, we will be able to make verifiable progress toward a defined notion of perfection in student performance (and yet perfection remains outside of what the reporting form allows programs to claim).

- Language use can be extracted from the messy varieties of everyday utterances (parole) and seen and measured as it relates to a targeted, context-transcendent system (langue).

- The program is organized in a way that enables it to be honed by the administrator to address deficits effectively. So the assumption is also that there is a stable and professional teaching cadre with adequate administrative support for emphasis and focus. 
My colleagues and I recognized in the approval and reporting process the "accountability" rhetoric that has become a central platform of national educational policy and instrumental in establishing the pervasiveness of testing in K-12 education. Objectivist assessments align with a labor model that technocratizes teaching and writing, seeking to convert it to measurable, manageable units. The assessment mandate compelled us toward methods of assessment that countered our constructivist understanding of all acts of reading, writing, and learning as socially situated and our understanding that standards are ideologically contended and socially produced.

Our requests for funding to develop a qualitative assessment were turned down (we were only given enough funding to pay scorers during scoring sessions). Fortunately, in a competitive process we secured a program-development grant to conduct a constructivist assessment with substantial qualitative elements that built on the dynamic criteria mapping (DCM) model developed by Bob Broad (2003). This model seeks to include teachers in every phase of the assessment, including the development of the assessment standards. While it generated aggregate numbers to satisfy the institutional requirement, the model was designed to be primarily descriptive rather than evaluative, a means of doing research on teaching and writing in our program and then using the findings to discuss the variety of practices and values that were present.

However, we still had to report out using the required form. The process we developed for the assessment had elements we could embrace: it helped us to foster deep, informed discussions among a portion of the writing faculty about what we value in writing, and it gave us the opportunity to collect, describe, and discuss the types of writing students were doing across the program. Nevertheless, the broader administrative process at the institution-how it solicited, circulated, and sought to use scores-remained unchanged and was philosophically incongruous with the view of writing education we sought to promote within the program. Regardless of how we performed the assessment, the administrative process converted the labor of teachers and students-which we qualitatively described and discussed in the local assessment-into flattened signifiers, a set of singular numbers that related to simply stated outcomes.

Below is the required set of numbers solicited within the process: an overall score accompanied by scores in five categories that aligned with the stated learning outcomes of the writing program. These numbers were obtained from a statistically significant sample of students' writing. 


\begin{tabular}{ccccccc}
\hline $\begin{array}{c}\text { Overall } \\
\text { Score }\end{array}$ & $\begin{array}{c}\text { Rhetorical } \\
\text { Awareness }\end{array}$ & Development & $\begin{array}{c}\text { Purpose/ } \\
\text { Writerly Ethos }\end{array}$ & Content & $\begin{array}{c}\text { Technical } \\
\text { Accuracy }\end{array}$ & $\begin{array}{c}\text { Overall } \\
\text { Average }\end{array}$ \\
\hline 2.95 & 2.9 & 2.75 & 3.5 & 2.9 & 3.2 & 2.95 \\
\hline
\end{tabular}

This representation was produced by the reporting requirements and circulated as a true and objective portrait of student learning in the first-year writing program. ${ }^{2}$ The representation, and the circumscribed method through which it was reported, depicts a program in which there is agreement on what good writing looks like; it has been measured competently, and the program is functioning adequately. Proficiency in this assessment was designated as 2.5, so we seemed to be doing better than the baseline. Administrators got an assessment that satisfied our accreditation body; there was no reason for concern and no obvious impetus for greater investment of resources.

Now I offer another set of numbers, another way of representing the writing program that originated from another set of values and another ideology of labor. As we conducted this assessment, we were also steadily arguing that the writing program was substantially underresourced. The table below presents a different portrait of the writing program at the time of the assessment.

\begin{tabular}{ll}
\hline Total number of sections of first-year writing for the year & 272 \\
\hline $\begin{array}{l}\text { Percentage of sections in the program taught by part-time teachers on one- } \\
\text { semester contracts }\end{array}$ & $58 \%$ \\
$\begin{array}{l}\text { Amount part-time faculty were paid per course } \\
\text { Amount of funding set aside annually for part-time benefits }\end{array}$ & $\$ 2,000$ \\
$\begin{array}{l}\text { Average annual turnover of part-time faculty } \\
\text { Average amount of experience of part-time faculty in the program }\end{array}$ & $31 \%$ \\
$\begin{array}{l}\text { Percentage of all instructors teaching in the writing program in this assessment } \\
\text { year who were teaching in the program during the prior assessment year }\end{array}$ & $<3$ years \\
$\begin{array}{l}\text { Designated annual budget allotment to the first-year writing program for profes- } \\
\text { sional development }\end{array}$ & 0 \\
$\begin{array}{l}\text { Number of tenure-line faculty who taught in the first-year writing program during } \\
\text { the assessment year }\end{array}$ & 0 \\
\begin{tabular}{l} 
Number of tenure-line faculty getting release time to administer the program \\
\hline
\end{tabular} & 1 \\
\hline
\end{tabular}

The second table portrays a program that is likely struggling, if not in disarray. Most of its teachers are working under exploitative terms; they are not very experienced, and they are turning over at a high rate. The administrative structure involves one tenure-line faculty member. Professional development is undersupported, with no guaranteed 
annual allotment. There is no ethical means of compelling most instructors to participate.

The first representation was generated in response to a mandate that carefully constrained what is reported and how. The second representation was not mandated by any reporting mechanism. Indeed, even outside of the assessment there was no established requirement to compile any of these numbers, and there was no established pathway to report them. Through focusing narrowly on the assessment of students' work (which was removed from the situations of its production) according to a handful of outcomes, the first representation created an order in which the onus of action was solely on the teachers and the WPA, carrying the underlying assumption that any deficits result from inadequate job performance rather than systematic institutional neglect; the second representation eroded the credibility of the assessment numbers as an indicator of the success and adequacy of the program structure and put the onus on the institution to create the professional conditions for success.

\section{THE POLITICAL ECONOMICS OF ASSESSMENT}

I want to turn now to explain some of the political economic logics at play in large-scale writing assessments like this one, and I will start with value. Value is a noun. In its noun form, a value is a property of something that can be expressed as an abstract signifier. The categories we use to assess writing are values but so also are the symbolic markers we produce. The noun form is the expression of exchange value. Some important characteristics of the noun form of value ( $a$ value) are its abstraction, its transferability, and its transcendence of the situations of production. We can assign an essay a 3 on a five-point scale, but the essay is not the 3. In terms of the assessment, the essay is a material object with rhetorical use-value that doesn't have any exchange value in circulation, but the generic value assigned to it, the 3 , does.

When we assign values to students' writing work we enter it into a closed economy of exchangeable signifiers. The relationship between valuation of writing and valuation of material commodities is parallel.

A student text $=3$

A pair of jeans $=\$ 50.00$

A unique piece of writing with use-value produced under singular conditions is given a generic exchange value that exists within an ordered economy of values. ${ }^{3}$ Likewise, a pair of jeans produced by real people under material terms is given an abstract exchange value for sale, 
represented in cost. This cost connects the commodity to an ordered system, an abstract economy of exchangeable values, and the terms of production are obscured.

When writing is produced for some purpose beyond a grade, but is also commodified through the assignation of a signifier within an established system of valuation, it becomes a contradictory unit of use-value and exchange value. Which brings me to the next point. Value is also a verb: it is material enactment. In assessment, valuation is a socially situated, ideologically shaped act performed by real people in specific circumstances. We value when we respond to work, when we grade work, and when we assess work on a large scale. The dual function of value as abstract signifier on one hand, and on the other as material labor performed by human beings, merits more focus. As assessments create economies of value, they create orders according to political economic ideologies that create tensions and contradictions between abstraction/ exchange value and materiality/use-value.

Much of Marx's (1990, 1993a) most important and influential work centers on his "labor theory of value," which describes the relationships among money, value, and commodities. The labor theory of value can help shed useful light on how large-scale assessments often function in academic institutions. In a classic, liberal theory of value, the basic formula for the relationship between money and commodities is expressed as $\mathrm{M}>\mathrm{C}>\mathrm{M}$, where money $(\mathrm{M})$ is exchanged for a commodity $(\mathrm{C})$ in an act of purchase: $M>G$. Then that commodity is sold again for money: $\mathrm{C}>\mathrm{M}$.

Marx (1993a) points out that through $\mathrm{M}>\mathrm{C}>\mathrm{M}$, something mysterious, seemingly even magical, happens to value: the value invested in the beginning of this process can increase or decrease by the end. So the M in the formula of exchange is not constant. In fact, an increase of value in this exchange, the creation of surplus value, is at the very heart of capitalist economics. This is a part of what is called the magic of the marketplace, and it looks no less miraculous than transubstantiation: as though it is invested with its own life and natural reproductive powers, money somehow creates more money. It defies elementary logic: from nothing comes something. This seems magical because at first glance market valuation seems to be based on equivalent exchanges. At the moment money is exchanged for a commodity, M1 > C, the money and the commodity, by market definition, have the same value: $\mathrm{M} 1=\mathrm{C}$. A chair costs $\$ 150$ : $\$ 150$ purchases a chair. However, the chair can then be sold at a different value: $\mathrm{C}>\mathrm{M} 2$; therefore $\mathrm{C}=\mathrm{M} 2$. Someone can purchase chairs at $\$ 150$ in one time and place, then sell them for $\$ 250$ at another time and place. 
Marx (1993a) uses this analysis of exchange as a cornerstone of much critique, but he was not just a quantitative researcher. Qualitative inquiry into terms of production and exchange enabled Marx to follow values through actual material processes of valuation, describing what is so often obscured in a liberal political economy. Marx didn't just work at the level of abstraction and representations of surplus (input and outcomes); he worked to describe the materiality of labor and how surplus is realized. This description is what makes Marx's theory of value a labor theory of value.

In capitalist economies, human beings sell their labor for money, and human time and energies become exchangeable commodities. Marx devised a labor theory of value to recognize that human labor power (LP) plus the material terms of production (MP) are included in the commodity.

$$
\mathrm{M} 1>\mathrm{C}[\mathbf{L P}+\mathbf{M P}]>\mathrm{M} 2
$$

In summary, the model of classic liberal economics seems to create the magic of increased value, of money somehow creating more money, because it emphasizes inputs and outputs, and its representations keep the terms of production and valuation (human labor) out of the equation. The focus is on the signifiers of values, the nouns, and not on valuation and the ongoing, ideologically driven and messy processes and terms of production. Our periodic individual retirement account (IRA) reports, for instance, may show steady long-term increases in symbolic indicators on tables, but nothing in the representations encourages us to understand how the surplus that leads to our investment gains is generated. Unless you believe in magic, though, capital does not increase in value on its own.

As a researcher of how labor relates to value, Marx painstakingly documented the terms of labor in nineteenth-century industry that are systematically ordered out of the liberal economic formula: the exploitation of children, working conditions that maimed and sometimes killed people and often took years off of their lives, conditions that kept people working long hours at wages that never enabled them to accumulate capital and sometimes didn't even enable them to acquire adequate nutrition or housing.

Valuation in assessment performs a similar function. Assessments create constrained representations of quality that render invisible many of the factors crucial to quality, such as the maintenance of a stable cadre of writing teachers who have professional status and benefits, are credentialed in the field in which they are teaching, and are supported 
within a professional-development structure that enables them to innovate and grow in relation to research. Through reducing valuation to the measurement of a handful of traits in students' work, large-scale writing assessments in higher education are used to create the deception of more for less.

\section{DEMOCRATIC ASSESSMENT AND ORDER}

Over the past decade, Bob Broad's (2003) innovative dynamic criteria mapping method has been very influential in writing assessment. Rightfully so: we drew heavily on the DCM model in the design of our assessment and were impressed with how it can make assessments meaningful for teachers and thus actually enhance pedagogy through the way it uses qualitative research methods. DCM assessments don't appeal to universal values through employing standard rubrics but rather conduct systematic qualitative research that surveys the faculty who work at the site of the assessment to ascertain their perceptions of what should be valued in writing. They then seek to foster a degree of local consensus at sites concerning what will be favored in the assessment of students' drafts. Students' work is assessed based on whatever consensus has been built using this qualitative-research and consensus-building process. There is an important egalitarian spirit in these models, and they do get at least partially down into the messy material labor of valuation as teachers and administrators perform it. Yet, for all of its promise, there are also significant problems in the ways these assessments are sometimes deployed.

In What We Really Value: Beyond Rubrics in Teaching and Assessing Writing, and in the introduction to Organic Writing Assessment, Broad (2003, 2009) variously characterizes DCM as "democratic," "communal," and "transformative" in addition to "organic." These characterizations create the familiar contrast mentioned above between an externally imposed assessment and system of order and one that is locally conceived and affords agency for the WPA. Summarizing the strengths of his organic model with the help of assessment participants' (teachers') quotations, Broad writes $(2003,21)$, "Participants in a recent DCM process wrote of their experiences: 'Helpful to hammer things out with colleagues' and 'this was the kind of conversation [writing faculty] needed to be doing all along.' .. . DCM also leads to a sense of ownership and belonging on the part of writing instructors-including teaching assistants and adjuncts-who see that they have a strong voice and a crucial role in articulating their program's values. Plus DCM is fun-an intellectual, 
rhetorical, and pedagogical party." DCM is cast as an empowering process of democratic consensus building, a tool for promoting ownership and buy-in, even a means of fostering a sense of belonging. The problem is the implication that there is a "natural" order in writing programs that has not been contaminated by externally imposed assessments that should be honored. In Broad's (2009) collection Organic Writing Assessment, most descriptions of democratically minded DCM-initiated assessments erase asymmetrical power relations among administrators, teachers, adjuncts, and teaching assistants. The result is that most of the assessments don't challenge how writing is perceived outside of programs, nor do they bring any attention to the professional status and terms of work of the largely part-time faculties who are tasked with doing their own assessments. The pervasive use of part-time teachers becomes an elephant in the room remarkable for its presence as a natural given and its absence as a point of focus. Indeed, it could be argued that assessments democratized in this way are unintentionally serving as palliative managerial measures that divert attention from deep issues in terms of work through providing innocuous opportunities for expressing a voice.

For instance, in a chapter in Organic Writing Assessment, Barry Alford (2009) describes an assessment that is democratic but also seamlessly aligns writing pedagogy with the Academic Quality Improvement Plan for general education undertaken at his institution, a state community college. Here the democratic process initiated by the assessment is used to better meet the mandates imposed by upper administration-mandates designed to monitor and order teaching. Noting that many of the faculty at his college teach a five-course-per-semester load, Alford lauds DCM for its efficiency: because DCM is "grounded in the work students were already doing" and it is "based on the values that faculty already had," DCM is "critical to making assessment work in an environment where resources and time are already at a premium" (37). Because it enabled his program to develop standard rubrics (aligned with the large-scale assessment), Alford contends that the assessment gave adjuncts a voice in the assessment of their work and gave them a "concrete" means of understanding values and outcomes (46). A concrete means of understanding values and outcomes that came "organically" from them? This seems to be democracy put to the purpose of a managerial accountability prerogative.

Jane Detweiler and Maureen McBride likewise describe an organic and democratic process of consensus building that also meets an institutional mandate to, as they put it, show upper administration "the precise ways that the program appeared to be succeeding 'by the numbers"” 
(Detweiler and McBride 2009, 65). In this description, the democratic and organic assessment is used by the WPA to prove success to upperlevel administration. Detweiler and McBride reveal that they were operating with limited funding when carrying out their organic assessment when they write, "We involved our instructors in revising teacher resources. For example, we asked for volunteers for a working group to look at examples of assignments from high-scoring (4.5 to 5.5 range overall) portfolios. We chose only high-scoring portfolios to ensure that the assessment did not become a critique of teaching. We had six volunteers meet for a Saturday with only a small bribe of homemade snacks and potential CV lines" (71). While qualitative, "local" models have the potential to describe the pervasive problems that result from the underresourcing of first-year writing education, in these descriptions of DCM there is no mention of problems with preparation, terms of work or oversight, and turnover among writing teachers. There is almost no acknowledgment of the differentiation of status among teaching faculty. One wonders why Detweiler and McBride were "bribing" firstyear writing teachers with the proxy wage of snacks and CV lines? Is it because they were unable to pay the instructors a real wage for their extra work? Why is the administration requiring proof of success without even paying for the assessment? In her critique of gender and labor exploitation in writing programs, Eileen Schell $(1998,40)$ writes about "psychic income," another form of proxy capital. Psychic income is the alleged privilege and status of teaching at a postsecondary institution and the gain of some temporary sense of professional status-one that isn't actually recognized or rewarded by the institution (see Scott 2009, 62-64). Most first-year writing faculty are part time and female, and women have traditionally been expected to do low-status work for psychic income. In my experience, people are willing to give up their free time to do unpaid work like this in writing programs because they are otherwise institutionally disenfranchised and are only able to compete for the types of low-level opportunities that would make such a line on a CV worthwhile. Moreover, many part-time instructors feel compelled to "volunteer" for unpaid work, in part because they are on short-term contracts and feel they must do whatever they can to ensure they continue to get work.

The language of democratization and the fostering of buy-in becomes, at the very least, complicated when we acknowledge the stark power differentials and exploitative practices that characterize so much of the scene of first-year writing instruction. Notably absent in descriptions of progressive, democratic writing assessments is any significant 
presence of tenure-line faculty, who typically don't teach the courses subjected to large-scale assessment (like first-year composition) and who usually require more than snacks or a CV line to be compelled to go into work on a Saturday to read portfolios. In these descriptions, democratic processes are put to use to meet administratively imposed assessment mandates designed to ensure quality without addressing the terms of labor and professional status of those who teach and perform the assessments. The democratic processes and qualitative writing assessments might be put to more activist, agentive uses. How might the scope and function of writing assessments change if the terms of labor became an essential component in how labor is represented and how performance is evaluated?

\section{TOWARD A LABOR THEORY OF WRITING ASSESSMENT}

In his critique of the relationship between colonialism and modernity, Walter D. Mignolo (2011) describes a "matrix of power" with two interrelating sides, which he argues poststructuralist and postcolonial perspectives never escape. One side of modernity is "constantly named and celebrated (progress, development, growth)"; the other side is "silenced or named as problems to be solved by the former (poverty, inequality, etc.)" (xviii). Mignolo goes on to describe how technology is joined with "free markets" and Western European- and Americansanctioned models of democratic governance in narratives in which growth and progress overcome crises. The rub is that it is so often the means of progress, development, and growth that cause the problems they are alleged to address. It is a self-perpetuating cycle of crisis production. The current wave of state-level "reforms" and the Obama administration's Race to the Top initiative build on the work of the Bush-era Spellings Commission. Claiming there is a crisis in higher education, the Obama initiative seeks a substantial restructuring of higher education through employing a raft of neoliberal efficiency measures that include curricular control mechanisms, privatization schemes, and plans to offer transcript credits based on assessed competencies rather than credit hours from completed classes. Of course, the 30-year decline in state spending per full-time enrolled student and the increasing reliance on contingent labor in higher education are not mentioned as factors in this "crisis."

Gallagher $(2011,45)$ very usefully connects the dots among government reforms, accountability, and the current concerted political effort to bring higher education more into alignment with neoliberalism. 
Accountability is the lever that will force U.S. higher education to recognize itself for, and start behaving as, what it is: both a competitor in a global market and itself a market in which individual institutions compete. Yet the commissioners leave "accountability" undefined, perhaps because it seems self-evident-and self-evidently good-within a neoliberal agenda. However, they frequently link the term to "transparency," suggesting that accountability consists of institutions furnishing evidence that they are good investments to those who foot the bill-that they add value to their (student-) products. In the report . . . we find repeated calls for a systematic, comprehensive, outcomes-based, and, above all, consumerfriendly database.

Unfortunately, the ways in which the field envisions WPA responsibilities and does writing assessment may be helping to facilitate this project. We do now have sophisticated constructivist assessment models that include democratic elements. The problem is that you can arrive at numbers that measure outcomes using a constructivist and democratic approach, but the numbers then circulate as objective truths about students' writing and the performance of teachers and the program-absent the qualitative elements that tell so much of the real story of postsecondary writing education. The terms of labor of writing and teaching-even the terms of labor for those who did the work of the assessment-are erased. The outcomes focus ignores a model for excellence in higher education based on professional expertise, research, and innovation and aligns with one in which drafts written in classes taught by seemingly any teachers working under any conditions meet acceptable thresholds for measurable outcomes in aggregate. The former, qualitative model puts emphasis on investment in the maintenance and support of a professional, credentialed cadre of teachers; the measurable outcomes-driven model aligns with a technocratized neoliberal model in which underpaid, often variously credentialed teachers are plugged into static curricula that focus primarily on those aspects of writing that can be measured reliably. Innovations that make assessment more democratic and consistent with contemporary understandings of literacy and learning don't escape the fundamental modernist narrative of narrowly determined growth through a regularization process that involves circumscribed goals, the commodification of labor and outcomes, and increased managerial control over intellectual work. I question the value of consensus-building processes that pave over the messiness on which consensus is built and arrive at neat, familiar orders that don't represent the materiality of writing and teaching labor or the ideologies of values. When the drive for consensus overshadows critical analysis and struggles for more resources and better terms of 
work, democratic processes can actually serve to bolster professionally and socially irresponsible structures and practices. Democracy becomes amelioration when alternative values are procedurally discarded and the truth behind the magic of more for less remains safely hidden.

The field must continue to work on developing qualitative assessment models but ones that are based on a labor theory of value and that incorporate the terms of labor into their notions of validity. These assessments should

- leave the question of what and how to value open from one assessment to the next, emphasizing dialogue about pedagogy and what is valuable in writing over the need to compare; Broad's DCM provides a good model for this;

- qualify any reporting of aggregate numbers as representing a singular set of values among others that might be equally legitimate; we did this in the assessment we implemented, in part by reporting two different sets of numbers from two different value systems so that no single number could be taken as the one accurate representation of performance in the program;

- include reporting of the terms of labor in the writing program, taking the opportunity of mandated assessment reports to publicize those terms, which we did as an addendum in the reports we filed; highlighting program facts like percentages of part-time faculty, lengths of contracts, levels of turnover, and allotments for professional development can undermine the mirage that many programs have the resources and stability to respond to issues raised in assessments from one assessment period to the next;

- preserve teaching and writing as creative, intellectual, collectively imagined endeavors; an assessment based on a labor theory of value recognizes that creativity is a basic right of all workers, and assessment cannot be used as a means of overdetermining labor or making its terms invisible.

Assessment issues are inescapably labor issues. Greater critical understanding of the politics of valuation and the political economic functions of assessments is crucial to achieving the educational ends assessment mandates purport to support but are too often designed to undermine. 


\section{Appendix 1.A}

Reflection on the Continuous Improvement of Student Learning

1. List the changes and improvements your program planned to implement as a result of last year's student learning outcomes assessment data.

2. Were all of the changes implemented? If not, please explain.

3. What impact did the changes have on student learning?

Student Learning Outcomes (Knowledge of Skill That Is to Be Assessed)

Changes to the Student Learning Outcomes Assessment Plan: If any changes were made to the assessment plan (which includes the Student Learning Outcome, Effectiveness Measure, Methodology and Performance Outcome) for this student learning outcome since your last report was submitted, briefly summarize the changes made and the rationale for the changes.

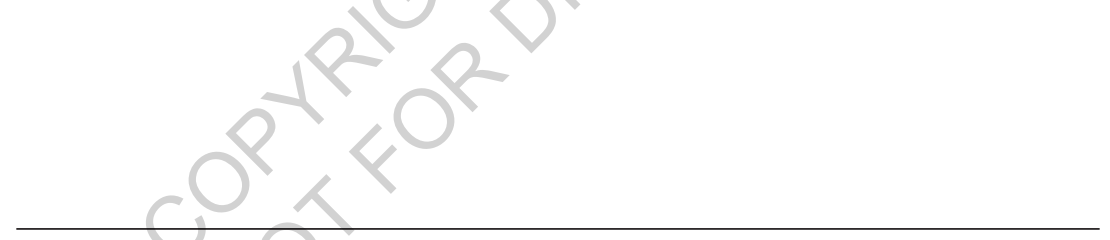

Effectiveness Measure: Identify the data collection instrument, e.g., exam, project, paper, etc. that will be used to gauge acquisition of this student learning outcome and explain how it assesses the desired knowledge, skill or ability. A copy of the data collection instrument and any scoring rubrics associated with this student learning outcome are to be submitted electronically to the designated folder on the designated shared drive and hyperlinked to the Effectiveness Measure. 
Methodology: Describe when, where and how the assessment of this student learning outcome will be administered and evaluated. Describe the process the department will use to collect, analyze and disseminate the assessment data to program faculty and to decide the changes/improvements to make on the basis of the assessment data.

Performance Outcome: Identify the percentage of students assessed that should be able to demonstrate proficiency in this student learning outcome and the level of proficiency expected. Example: $80 \%$ of the students assessed will achieve a score of "Proficient" or higher on the Oral Presentation Scoring Rubric. (Note: a copy of the scoring rubric, complete with cell descriptors for each level of performance, is to be submitted electronically to the designated folder on the designated shared drive and hyperlinked to the Effectiveness Measure above for each student learning outcome.)

\section{Notes}

1. These events happened at an institution at which I am no longer employed.

2. We did subvert this somewhat in our reporting. Because we didn't want any singular standard to stand as a universal set of values, we evaluated the students' work using two different perspectives and reported two sets of numbers as equally valid.

3. I realize that the degree to which writing produced in school settings has use-value varies and depends on how students' writing is solicited and circulated. Much writing produced in school doesn't have any circulation beyond the teacher and isn't produced for any clear purpose beyond performance for a grade. It is produced purely for exchange value, making the writing alienated labor. Also, though I don't have the opportunity to develop the point in this essay, parole/langue certainly parallels use/exchange, as the latter requires stability and is undermined by variety. 